Article

\title{
Iron Exposure and the Cellular Mechanisms Linked to Neuron Degeneration in Adult Mice
}

\author{
Lin-Bo Li, Rui Chai, Shuai Zhang, Shuang-Feng Xu, Yan-Hui Zhang, Hai-Long Li, \\ Yong-Gang Fan and Chuang Guo *
}

College of Life and Health Sciences, Northeastern University, Shenyang 110819, China; 18640176710@163.com (L.-B.L.); m1537307231@163.com (R.C.); icnmif@126.com (S.Z.); 13804021867@163.com (S.-F.X.); zhangyanhui@cmu.edu.cn (Y.-H.Z.);

LiHailong1166@gmail.com (H.-L.L.); 18841609869@163.com (Y.-G.F.)

* Correspondence: guoc@mail.neu.edu.cn

Received: 6 December 2018; Accepted: 19 February 2019; Published: 24 February 2019

\begin{abstract}
Although the causal relationship between Alzheimer's disease (AD) and iron overload remains unclear, iron dyshomeostasis or improper transport mechanisms are speculated to lead to the accumulation of this neurotoxic metal in the hippocampal formation and other cerebral areas related to neurodegenerative diseases, resulting in the formation of reactive oxygen species (ROS) and, ultimately, cell death. In this study, exposure to high dietary iron (HDI) revealed no significant difference in the number of iron-positive cells and iron content in the cortex and hippocampal region between wild-type (WT) and APP/PS1 mice; however, compared with the control mice, the HDI-treated mice exhibited upregulated divalent metal transporter 1 (DMT1) and ferroportin (Fpn) expression, and downregulated transferrin receptor (TFR) expression. Importantly, we confirmed that there were significantly fewer NeuN-positive neurons in both APP/PS1 and WT mice given $\mathrm{HDI}$, than in the respective controls. Moreover, this iron-induced neuron loss may involve increased ROS and oxidative mitochondria dysfunction, decreased DNA repair, and exacerbated apoptosis and autophagy. Although HDI administration might trigger protective antioxidant, anti-apoptosis, and autophagy signaling, especially in pathological conditions, these data clearly indicate that chronic iron exposure results in neuronal loss due to apoptosis, autophagy, and ferroptosis, hence increasing the risk for developing AD.
\end{abstract}

Keywords: Alzheimer's disease; iron; neuron loss; apoptosis; autophagy; ferroptosis

\section{Introduction}

Alzheimer's disease (AD) is the most common neurodegenerative disease, and is characterized by senile plaques (SPs) formed from $\beta$-amyloid (A $\beta$ ) [1] and neurofibrillary tangles (NFTs) composed of tau protein [2]. Both SPs and NFTs decrease synaptic plasticity and neuronal connectivity and lead to neuron dysfunction and death, ultimately resulting in cognitive damage and dementia [3].

Studies have implicated cellular overload of iron, a necessary cofactor in many metabolic processes in the central nervous system, along with iron-induced oxidative stress, in the development of AD [4-6]. Excessive iron levels may lead to the dissociation of iron regulatory proteins (IRPs), which function as cytosolic iron sensors, from their iron responsive element (IRE) binding sites and abolish their repression of APP mRNA, resulting in enhanced APP translation [7]. In contrast, the translation of APP mRNA and A $\beta$ generation can be inhibited by chemical IRE inhibitors [7]. Furthermore, iron is able to bind to $A \beta$, induce $A \beta$ aggregation, accelerate the formation of oligomers, and enhance the toxicity of A $\beta$ [8]. Interestingly, there is some evidence that APP aids iron export from neurons through its interaction with ferroportin (Fpn), and APP knockout mice reveal markedly increased hippocampal 
and cortical neuronal iron and oxidation [9]. Emerging evidence suggests that $\operatorname{sAPP} \alpha$, a cleavage product of the non-amyloidogenic pathway, stabilizes Fpn in the neuronal membrane, supporting the neuroprotective properties of APP $[9,10]$.

In addition to $A \beta$, iron has been found to be relevant to the formation of NFTs in AD patient brains $[11,12]$. Furthermore, iron has the ability to bind to hyperphosphorylated tau and cause tau aggregation in vitro [13]. In an in vivo mouse model of AD, iron exposure induced tau hyperphosphorylation [14,15], which can occur under conditions of increased oxidative stress [16,17]. On a similar note, another study suggested that the loss of soluble tau may contribute to iron retention in the brain in tau-knockout mice and in primary cultured neurons [18]. Furthermore, iron levels have been verified to be significantly higher in the brains of P301S transgenic mice, which carry the human Tau gene with the P301S mutation, than in the brains of wild-type (WT) mice, whereas iron chelation treatment with $\alpha$-lipoic acid (LA) (a naturally occurring enzyme cofactor with antioxidant and iron chelator properties) has neuroprotective potential due to mitigating oxidative stress, inflammation, neuronal degeneration, and tauopathy, through the redistribution of iron in specific areas of the mouse brain associated with neurodegeneration [19]. Based on these findings, whether excess iron exposure plays a mechanistic role in amyloid and/or tau pathology, and whether APP and/or tau pathology disrupt local iron homeostasis, remain unclear.

Of course, pathological neuronal iron accumulation has been observed in AD brains $[9,20]$. Increasing evidence suggests that SPs and NFTs are involved in neurotoxicity [21], apoptosis [22], autophagy [23], ferroptosis [24], oxidative stress [25], and DNA damage [26] during AD development and progression. Further support for the interlinkage between iron metabolism and AD comes from the observations that therapeutic strategies using iron chelators and/or IRE inhibitors may attenuate SPs and NFTs, as well as prevent neuron loss, in various in vivo AD models [7,27]. As such, the types of cell death that are responsible for the bulk of neuronal loss in AD in the absence or presence of excess iron remains unclear. Here, we hypothesized that excess iron exposure may exaggerate age-dependent, amyloid-mediated neurotoxicity and neuronal dysfunction. Therefore, we sought to determine the molecular mechanism responsible for this dysfunction using APPSwe/PS1DE9 (APP/PS1) mice and littermate C57BL/6J mice.

In this study, we evaluated the forms of neuron death and their mechanisms in WT mice and the APP/PS1 double Tg mouse model of AD after treatment with high iron in the drinking water. We detected factors related to neurotoxicity, apoptosis, autophagy, ferroptosis, oxidative stress, and DNA damage. Our results showed that a high level of iron-induced neuron death is caused by a mixture of factors in both the normal and pathological conditions.

\section{Materials and Methods}

\subsection{Animals and Treatment}

APP/PS1 (APPswe/PSEN1dE9) double Tg mice and C57BL/6J (WT) mice were originally obtained from Jackson Laboratory (West Grove, PA, USA). The mice were maintained in a controlled environment $\left(22-25^{\circ} \mathrm{C}, 40-60 \%\right.$ relative humidity, and $12 \mathrm{~h}$ light/dark cycle), with a standard diet and distilled water available ad libitum. For subsequent experiments, we intercrossed these mice to generate APP/PS1 and WT littermate mice. All experimental procedures using animals were designed to minimize suffering and the number of subjects used. These studies were conducted in accordance with the guidelines for the care and use of medical animals developed by the Ministry of Health of the People's Republic of China (1998), and the ethical standards for laboratory animals in Northeastern University (\#161031).

We divided the 9-month-old male mice into four groups: C57BL/6J (WT), C57BL/6 J + Fe $(\mathrm{WT}+\mathrm{Fe}), A P P / P S 1(\mathrm{AD})$ and $A P P / P S 1+\mathrm{Fe}(\mathrm{AD}+\mathrm{Fe})(n=8$ in each group). The high-iron groups were treated with $5 \mathrm{~g} / \mathrm{L}$ ferric ammonium citrate (FAC) (Sinopharm Chemical Reagent Co., Ltd., Beijing, China) for three months, and the control groups (C57BL/6J and APP/PS1) were given distilled water. 


\subsection{Tissue Preparation}

Three months later, control- and FAC-treated mice were anesthetized with sodium pentobarbital (50 mg/ $\mathrm{kg}$, intraperitoneally) and then transcardially perfused with $0.9 \%$ saline. After the blood was completely perfused, the mouse brain was then immediately removed and cut in half on an icy plate along the sagittal plane. One half of the brain was retained in $4 \%$ paraformaldehyde for morphological evaluation, and the other half was frozen at $-80^{\circ} \mathrm{C}$ for the molecular biology experiments.

\subsection{Perl's-Diaminobenzidine (DAB) Iron Staining}

The frozen brain sections were hydrated with distilled water for $5 \mathrm{~min}$. Then, a mixture of $2 \%$ $\mathrm{K}_{4}\left[\mathrm{Fe}(\mathrm{CN})_{6}\right]$ (Sinopharm Chemical Reagent Co., Ltd., Beijing, China) and $\% \mathrm{HCl}$ was dropped on sections, followed by incubation at room temperature for $30 \mathrm{~min}$. After being washed three times by $0.01 \mathrm{M}$ PBS, the sections were stained with diaminobenzidine (DAB) dye solution (30 $\mathrm{mg}$ DAB (Beijing Labeled Biotech CO., LTD, Beijing, China) + $200 \mathrm{~mL}$ TrisHCL $+60 \mu \mathrm{L} \mathrm{30} \% \mathrm{H}_{2} \mathrm{O}_{2}$ ) for $3 \mathrm{~min}$, with observation under an optical microscope. The microscopic brown particles were considered positive staining. Images of stained sections were collected on a light microscope (DM4000B; Leica, Wetzlar, Germany). After three repeated experiments, the images were quantified using ImageJ analysis software (Version 4.0, National Institutes of Health, Rockville, MA, USA), and the area of positive staining was counted. Then, Graphpad prism software (Version 5.0, Graphpad, La Jolla, CA, USA) was used for differential analysis. Subsequent staining results were analyzed using the same method.

\subsection{Atomic Absorption Spectroscopy (AAS)}

Brain tissue samples were accurately weighed with an analytical balance, and the samples were treated with $200 \mu \mathrm{L}$ concentrated nitric acid at $98{ }^{\circ} \mathrm{C}$ for $15 \mathrm{~min}$. After cooling to room temperature, the samples were diluted to $5 \mathrm{~mL}$ with $1 \%$ nitric acid. A graphite furnace atomic absorption spectrometer (ZEEnit700P, Analytikjena, Jena, Germany) was used to detect the iron level.

\subsection{Immunohistochemistry (IHC)}

The mouse brain was removed from $4 \%$ paraformaldehyde, dehydrated, embedded in paraffin, and finally cut into $5 \mu \mathrm{m}$ sections. The coronal paraffin sections were then dewaxed and rehydrated, and treated with endogenous peroxidase inhibitor (MXB Biotechnologies, Fuzhou, China) for $10 \mathrm{~min}$. L.A.B solution (Polyscience, Inc., Niles, IL, USA) was added for $20 \mathrm{~min}$ to retrieve the antigens. After each treatment, the sections were washed three times with $0.01 \mathrm{M}$ PBS for 5 min each time, and blocked with goat serum for $30 \mathrm{~min}$. Then, the sections were incubated with only one primary antibody overnight at $4{ }^{\circ} \mathrm{C}$. The primary antibodies used for immunohistochemistry were rabbit anti-GFAP (1:400, Sigma-Aldrich, Philadelphia, PA, USA) and rabbit anti-ionized calcium-binding adapter molecule 1 (Iba1) (1:400, Cell Signaling Technology, Danvers, MA, USA). Next, the sections were treated with the corresponding biotinylated secondary antibody (MXB Biotechnologies, Fuzhou, China) for $1 \mathrm{~h}$ at room temperature, and then treated with HRP-streptavidin for $30 \mathrm{~min}$. The staining steps were identical to Perl's-DAB iron staining. The samples were then immersed in distilled water to stop the reaction, and finally counterstained with hematoxylin. After these steps were completed, the sections were dehydrated and sealed. Images of the stained sections were collected using an optical microscope (DM4000B; Leica, Wetzlar, Germany).

\subsection{Immunofluorescence (IF)}

The frozen brain sections were rehydrated and treated with L.A.B. solution (Polyscience, Inc., Niles, IL, USA) for $20 \mathrm{~min}$. They were then blocked with goat serum for $30 \mathrm{~min}$, and incubated overnight at $4{ }^{\circ} \mathrm{C}$ with both the mouse-anti-A $\beta$ (1:400) and rabbit-anti-NeuN (1:400, Cell Signaling Technology, Danvers, MA, USA) antibodies. Subsequently, sections were incubated in DyLight 594-labeled goat anti-mouse IgG and 488-labeled goat anti-rabbit IgG (1:400, Cell Signaling 
Technology, Danvers, MA, America) at room temperature for $1 \mathrm{~h}$. Finally, the sections were labeled with 4',6-diamidino-2-phenylindole (DAPI) (Beyotime Institute of Biotechnology, Beijing, China) and sealed with anti-fluorescence quencher (Beyotime Institute of Biotechnology, Beijing, China). The sections were observed and photographed using a confocal fluorescence microscope (Leica, SP8., Wetzlar, Germany).

\subsection{Nissl Staining}

The frozen brain sections were hydrated with distilled water for $5 \mathrm{~min}$, incubated in Nissl staining solution (Beyotime Institute of Biotechnology, Beijing, China) for $10 \mathrm{~min}$ at room temperature, washed twice with distilled water for a few seconds, and placed into $95 \%$ ethanol for 5 min, followed by $100 \%$ ethanol for $2 \mathrm{~min}$. The sections were then cleared with xylene for $10 \mathrm{~min}$ and sealed. The images of the stained sections were collected with a light microscope (DM4000B; Leica, Wetzlar, Germany).

\subsection{Western Blotting}

Mouse brain homogenates were lysed in RIPA buffer (Beyotime Institute of Biotechnology, Beijing, China) containing protease inhibitor cocktail, and then centrifuged at 13,000 r/min for $25 \mathrm{~min}$ at $4{ }^{\circ} \mathrm{C}$. The supernatants were collected, and the total protein levels were measured using an ultraviolet (UV) 1700 PharmaSpec ultraviolet spectrophotometer (Shimadzu, Tokyo, Japan). Thirty micrograms of protein were loaded onto 10\% SDS polyacrylamide gels, and transferred onto polyvinylidene fluoride (PVDF) membranes (Millipore, Billerica, MA, USA). After the membranes were blocked with 5\% nonfat milk in TBS containing $0.1 \%$ Tween-20 for $1 \mathrm{~h}$, the transferred PVDF membranes were probed overnight with the following antibodies: goat anti-AIF (1:2000; Santa Cruz Biotechnology, Dallas, TX, America), rabbit anti-Bax (1:1000; Santa Cruz Biotechnology), mouse anti-Bcl-2 (1:1000; Santa Cruz Biotechnology), mouse anti-Beclin-1(1:3000; Santa Cruz Biotechnology), rabbit anti-caspase 3 (1:1000; Cell Signaling Technology), rabbit anti-DMT1 (1:1000; Cell Signaling Technology), rabbit anti-Fpn (1:1000; Cell Signaling Technology), mouse anti-GFAP (1:1000; Santa Cruz Biotechnology), rabbit anti-GPX4 (1:1000; Santa Cruz Biotechnology), rabbit anti-Iba1 (1:1000; Abcam), rabbit anti-LC3 A/B (1:3000; Cell Signaling Technology), rabbit anti-MTH1 (1:1000; Santa Cruz Biotechnology), rabbit anti-m-TOR (1:1000; Cell Signaling Technology), mouse anti-MUTYH (1:3000; Santa Cruz Biotechnology), mouse anti-OGG1 (1:2000; Santa Cruz Biotechnology), rabbit anti-P62 (1:1000; Cell Signaling Technology), rabbit anti-PARP1 (1:1000; Santa Cruz Biotechnology), rabbit anti-p-m-TOR (1:1000; Cell Signaling Technology), rabbit anti-SOD1 (1:1000; Cell Signaling Technology), mouse anti-TFR(1:1000; Cell Signaling Technology), rabbit anti-xCT (1:1000; Abcam, Cambridge, UK), and mouse anti- $\beta$-actin (1:10000; Cell Signaling Technology). The immunoblots were washed and treated with the appropriate species of horseradish peroxidase (HRP)-conjugated secondary antibody (1:10000; Beijing Zhongshan Jinqiao Biotechnology Co., Ltd., Beijing, China), and immunological complexes were visualized by enhanced chemiluminescence (ECL) kits (Tanon, Shanghai, China) using the ChemiDoc XRS system and the accompanying Quantity One software (Bio-Rad, Hercules, CA, USA). The immunoreactive bands were quantified using ImageJ analysis software.

\subsection{Detection of Malondialdehyde (MDA) and Reactive Oxygen Species (ROS)}

The brain tissue was placed in 0.1 M PBS solution at a 1:9 ratio of brain tissue (g) to PBS volume $(\mathrm{mL})$, ultrasonically fragmented, and centrifuged at $1000 \mathrm{r} / \mathrm{min}$ for $10 \mathrm{~min}$. The supernatant was removed, and the protein concentration was determined. The relevant indicators were then measured using commercial assay kits (Jiancheng Biochemical, Nanjing, China). In brief, the ROS levels were measured by adding $5 \mu \mathrm{L}$ of supernatant and $195 \mu \mathrm{L}$ of $2^{\prime}, 7^{\prime}$-dichlorofluorescein diacetate (DCFH-DA) (Jiancheng Bioengineering Institute, Nanjing, China) to a 96-well plate, which was incubated for $30 \mathrm{~min}$ at $37^{\circ} \mathrm{C}$ in the dark. Fluorescence detection was then carried out using an excitation wavelength of $500 \mathrm{~nm}$ and an emission wavelength of $525 \mathrm{~nm}$ (Synergy/H1, BioTek, Jiangsu, China). The detection result was expressed by the fluorescence value/mg protein. Malondialdehyde (MDA) levels were 
assessed following the manufacturer's instructions, and the samples were incubated at $95{ }^{\circ} \mathrm{C}$ for $40 \mathrm{~min}$. The absorbance was measured at $532 \mathrm{~nm}$ to calculate the MDA levels, which were expressed as nmol per mL. Protein concentrations were measured by a BCA protein assay (Beyotime Biotechnology, Beijing, China).

\subsection{Statistical Analysis}

All results were obtained from three repeated experiments and presented as the mean \pm SEM. The difference between groups was analyzed by the unpaired two-tailed Student $t$ test for the two data sets, or the one-way analysis of variance (ANOVA) for the four data sets. The results were reported to be highly statistically significant if $p<0.01$, and statistically significant if $p<0.05$.

\section{Results}

3.1. Effect of High Dietary Iron (HDI) on Iron and Iron-Transport-Related Proteins in the Wild-Type (WT) and APP/PS1 Mouse Brain

To investigate the reason for the HDI-induced neurodegeneration in the mouse brain, we first examined the level of iron and iron-related transporter proteins. Perl's-DAB iron staining showed that HDI increased the number of iron-positive cells in the cortex and hippocampal region in WT and APP/PS1 mice (Figure 1A), however the increase was not statistically significant in the brains of either WT or APP/PS1 mice after treatment with HDI (Figure 1B, $p>0.05$ ). Simultaneously, we used AAS to evaluate the iron content (Figure 1C), and the results suggested that iron levels were significantly higher in the brains of APP/PS1 mice than in WT mice, but HDI did not statistically alter the iron content in the brains of either WT or APP/PS1 mice. Next, we examined the effect of HDI on the expression of transferrin receptor (TFR), divalent metal transporter 1 (DMT1), and Fpn-the only iron export protein of neurons (Figure 1D,E). TFR expression in the brain was significantly decreased after HDI treatment in both WT and APP/PS1 mice (Figure 1(D1,E1), $p<0.05$ or $p<0.01$, respectively). Nevertheless, the expression of DMT1 and Fpn was significantly increased after HDI treatment in both the WT and APP/PS1 mouse brains (Figure 1(D2,E2,D3,E3), $p<0.05$ or $p<0.01$, respectively). These results suggested that exogenous iron might penetrate the blood-brain barrier (BBB) and enter into the central nervous system (CNS) of adult mice, to induce iron redistribution by regulating the expression and function of brain iron-transport-related proteins.

\subsection{Effect of HDI on Neurodegeneration in the WT and APP/PS1 Mouse Brain}

To characterize the effects of HDI on the neuropathology of AD, we assessed changes in $\mathrm{A} \beta$ plaques, neurons, glial cells, and associated marker proteins in the brains of APP/PS1 mice and WT littermate controls at 12 months of age. As shown in Figure 2A, immunofluorescence demonstrated that HDI obviously decreased the fluorescence intensity of NeuN-positive neurons in the cortex and hippocampus of the WT and APP/PS1 mouse brains, relative to their respective controls (Figure 2(A1), $p<0.05$ or $p<0.01$, respectively). Meanwhile, the NeuN-positive neurons in the cortex and hippocampus of HDI-treated APP/PS1 mice were apparently reduced compared with HDI-treated WT mice, accompanied by an increase of A $\beta$-positive plaques (Figure 2(A1,A2), $p<0.05$ or $p<0.01$, respectively). We then aimed to define the functional state of these neurons in the cortex and hippocampus by Nissl staining. In both tissues, Nissl body levels were decreased by HDI treatment in both APP/PS1 mice and WT littermate controls (Figure 2(B,B1), $p<0.05$ or $p<0.01$, respectively), suggesting that HDI treatment inhibits the activity of neurons. We also examined NeuN protein expression in the brain tissues of HDI-treated APP/PS1 mice and WT mice, and found that NeuN protein expression was markedly downregulated compared to that in the respective controls (Figure 3(A1,B1), $p<0.05$ or $p<0.01$, respectively). This is consistent with the idea that chronic excess iron exposure might significantly undermine the structure and functions of specific neurons, ultimately causing neuronal loss. 
A

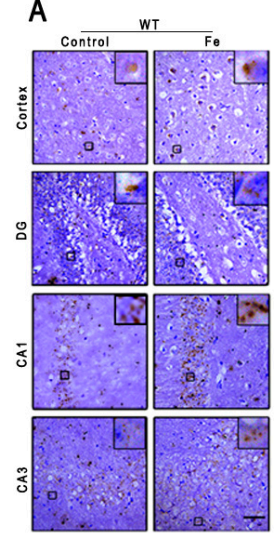

B

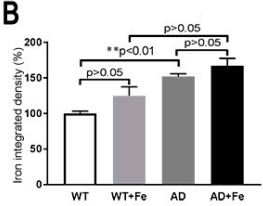

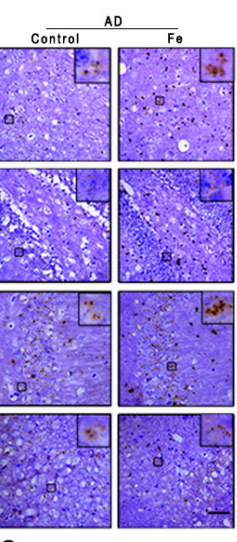

C

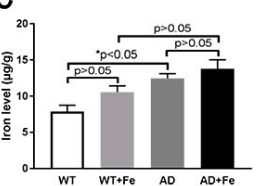

D

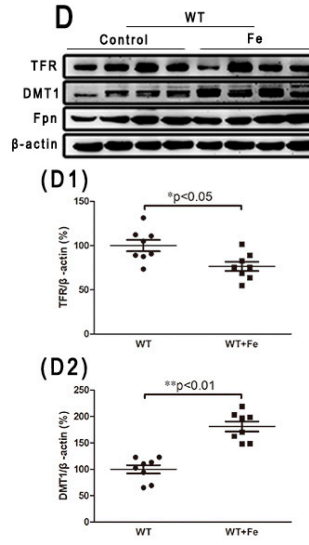

E

control $A D$

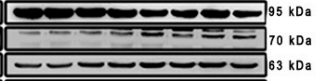

-

${ }^{120}+{ }^{30 p} p_{001}$

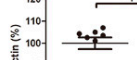

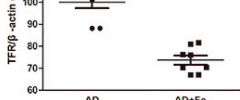

(D3)

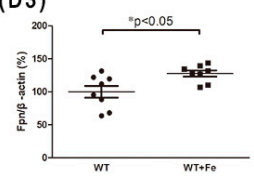

Figure 1. Effect of high dietary iron on iron and iron-transport-related proteins in the mouse brain. (A) Perl's diaminobenzidine (DAB) iron staining showed that high dietary iron (HDI) could increase the number of iron-positive cells in the cortex and hippocampal region of wild-type (WT) and APP/PS1 mice. (B) Quantitative analyses of Perl's-DAB iron staining. Scale bar $=50 \mu \mathrm{m}$. (C) The results of iron atomic absorption spectroscopy (AAS). (D, E) Western blot analysis of transferrin receptor (TFR), divalent metal transporter 1 (DMT1) and ferroportin (Fpn). (D1-D3, E1-E3) Quantitative analyses of Western blot for TFR, DMT1 and Fpn. $\beta$-actin was used as an internal control. All results are presented as the mean \pm standard error of the mean (SEM) $(n=8) .{ }^{*} p<0.05,{ }^{* *} p<0.01$ compared with the control group.
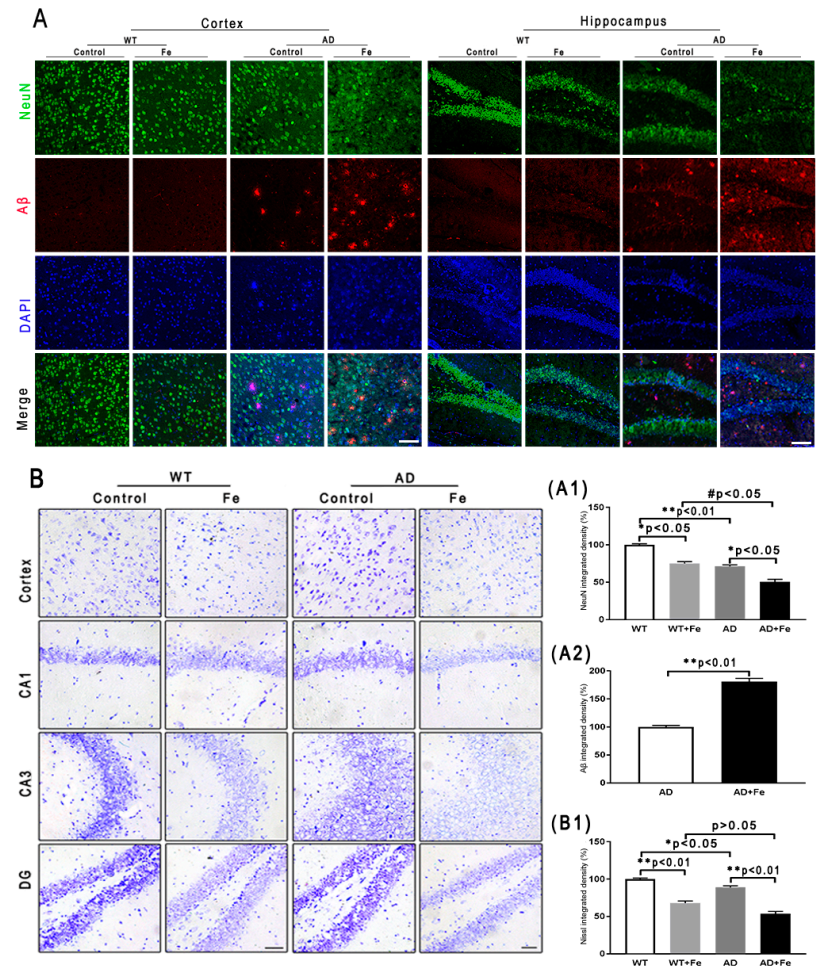

Figure 2. (A) Immunofluorescence of $A \beta$ and NeuN. Scale bar $=25 \mu \mathrm{m},(\mathbf{A 1}, \mathbf{A 2})$ Quantitative analyses of Neun-positive staining and $A \beta$-positive staining. (B) Nissl staining in the mouse brain. Scale bar $=25 \mu \mathrm{m}$. (B1) Quantitative analyses of Nissl-positive staining, $n=8 .{ }^{*} p<0.05,{ }^{* *} p<0.01$ compared with the control group; \# $p<0.05$ compared with the iron-treated WT group. 


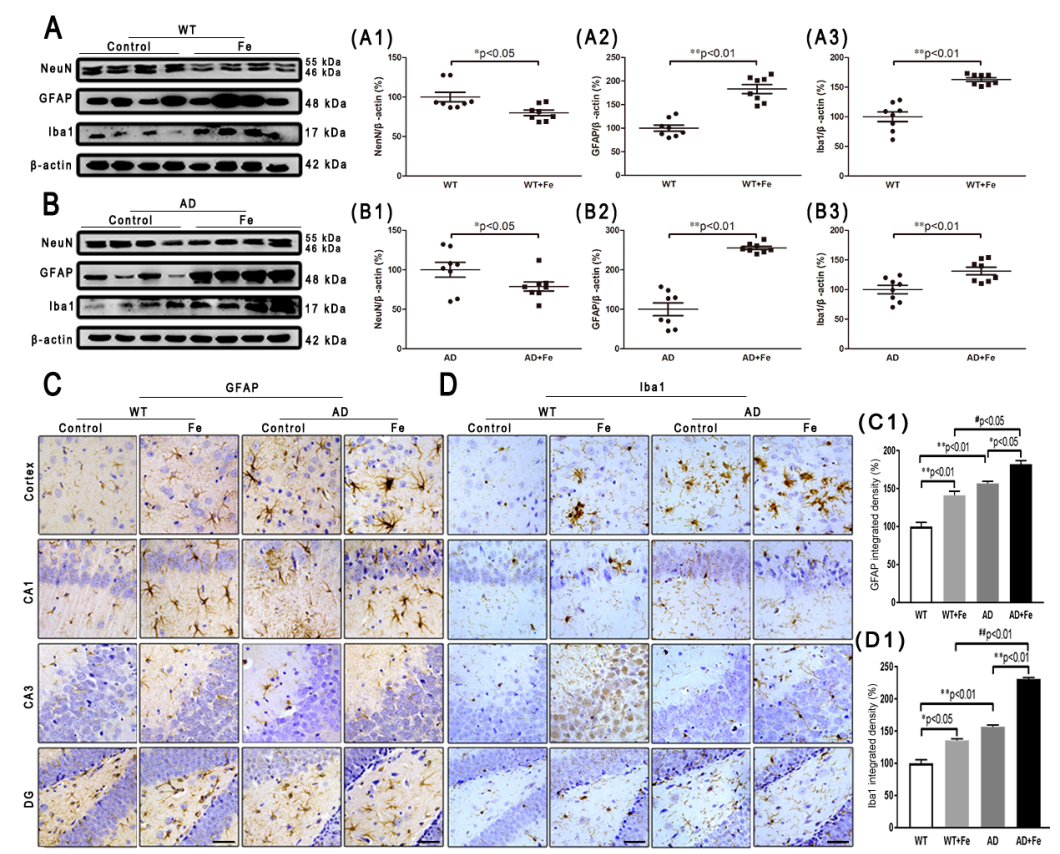

Figure 3. Effect of HDI on neurons and glia. (A, B) Western blot analysis of NeuN, glial fibrillary acidic protein (GFAP) and ionized calcium-binding adapter molecule 1 (Iba1). (A1-A3, B1-B3) Quantitative analyses of Western blot for NeuN, GFAP and Iba1. $\beta$-actin was used as an internal control. (C, D) Immunohistochemistry staining of GFAP and Iba1. (C1, D1) Quantitative analyses of GFAP-positive astrocytes staining and Iba1-positive microglia staining. Scale bar $=50 \mu \mathrm{m}$. All results are presented as the mean $\pm \operatorname{SEM}(n=8) .{ }^{*} p<0.05,{ }^{* *} p<0.01$ compared with the control group; $\# p<0.05$, \# \# $p<0.01$ compared with the iron-treated WT group.

As with neurons, glial cells are also involved in the regulation of iron homeostasis in the brain [28]. The Western blot results (Figure 3A,B) revealed a significant increase in the expression level of glial fibrillary acidic protein (GFAP) and ionized calcium-binding adapter molecule 1 (Iba1) in the WT and APP/PS1 mouse brains after HDI (Figure 3(A2,A3,B2,B3), $p<0.05$ or $p<0.01$, respectively). Simultaneously, in both the cortex and hippocampus of HDI-treated WT and APP/PS1 mice, immunohistochemistry staining demonstrated a sharp increase in GFAP-positive astrocytes and Iba1-positive microglia, with thick processes and enlarged somata (Figure $3(\mathrm{C}, \mathrm{D}, \mathrm{C} 1, \mathrm{D} 1), p<0.05$ or $p<0.01$, respectively), indicating activation of astrocytes and microglia, respectively. Although previous morphological analysis has indicated that $\mathrm{AD}$ tissue is associated with activated microglia and $A \beta$ plaques $[29,30]$, whether the cells lacking $A \beta$ plaques are microglia is not readily apparent.

These results indicated that HDI could distinctly activate glial cells and increase $A \beta$-induced neuroinflammation in the APP/PS1 mouse brain.

\subsection{HDI-Induced Redox Status and DNA Damage Depends Upon A $\beta$ Status in the Mouse Brain}

Iron is potentially toxic due to the generation of free radicals and ROS through the Fenton reaction. However, the human body is equipped with detoxifying mechanisms that alter redox regulation, and can even repair damage caused by reactive species [31]. To examine whether similar metabolic changes occur in HDI-treated WT and APP/PS1 mouse brains, we performed a series of experiments to detect the oxidative stress index and endogenous antioxidants. As shown in Figure 4, chronic iron exposure was associated with enhanced ROS and MDA, suggesting that HDI increased the level of free radicals and induced and aggravated oxidative stress in both the $\mathrm{WT}$ and APP/PS1 mouse brains, especially in the former. Glutamate-cystine transporter $(\mathrm{xCT})$ is a cystine-glutamate antiporter. It transports extracellular cystine into cells, which is converted to cysteine for glutathione (GSH) synthesis [32]. Glutathione peroxidase 4 (GPX4) is an intracellular 
antioxidant enzyme that reduces the production of phospholipid peroxide in cell membranes [32]. Superoxide dismutase (SOD1) is a $\mathrm{Cu} / \mathrm{Zn}$ superoxide dismutase, a major antioxidant enzyme that catalyzes the conversion of superoxide into hydrogen peroxide and molecular oxygen. In this study, HDI-treated WT mice showed significantly higher expression levels of $x \mathrm{CT}$, GPX4, and SOD1 than the nontreated controls (Figure 4(A,A1-A5), $p<0.05$ or $p<0.01$, respectively). Conversely, the expression levels of these antioxidants were significantly decreased in the APP/PS1 mouse brains after HDI treatment (Figure 4(B,B1-B5), $p<0.05$ or $p<0.01$, respectively). These results suggested that the brain may trigger a compensatory response to iron-induced oxidative damage under normal physiological conditions, while the compensatory response is severely inhibited in conditions of $A \beta$ accumulation.
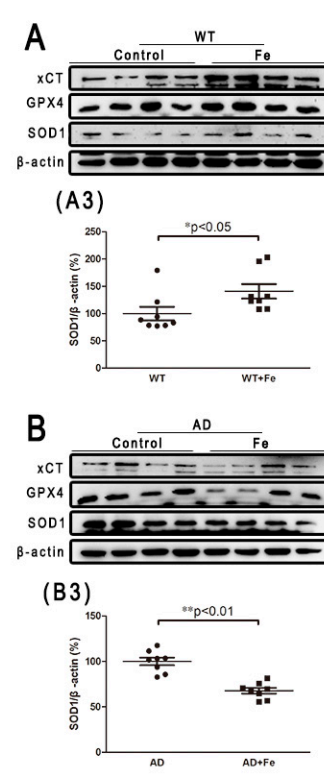

(A 1)

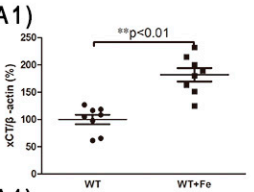

(A4)

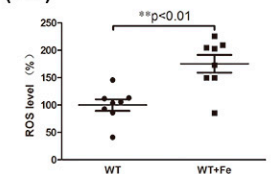

(B1)

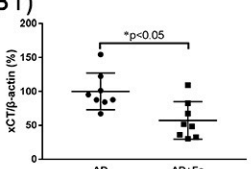

(B4)

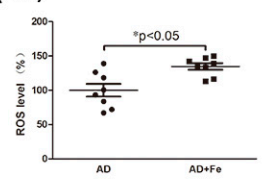

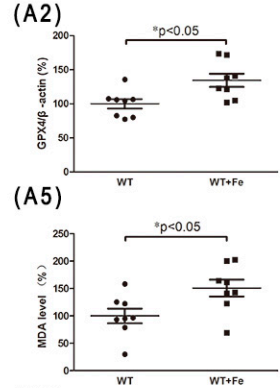

(B2)

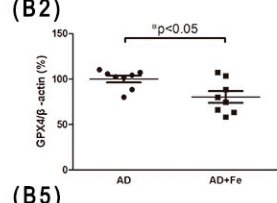

(B5)

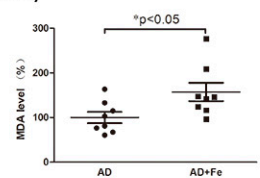

Figure 4. HDI-induced redox status in the mouse brain. (A, B) Western blot analysis of glutamate-cystine transporter (xCT), glutathione peroxidase 4 (GPX4), and superoxide dismutase (SOD1). (A1-A3, B1-B3) Quantitative analyses of Western blot for XCT, GPX4, and SOD1. $\beta$-actin was used as an internal control. (A4, A5, B4, B5) Quantitative analyses of reactive oxygen species (ROS) and malondialdehyde (MDA). All results are presented as the mean $\pm \operatorname{SEM}(n=8) .{ }^{*} p<0.05,{ }^{* *} p<0.01$.

Additionally, in order to detect iron-induced oxidative DNA damage, several DNA damage repair proteins, including mammalian MutY homologous DNA glycosidase (MUTYH), 8-hydroxyguanine DNA glycosidase (OGG1) and 8-hydroxy guanine nucleotidase (MTH1), were employed. After HDI treatment, the expression levels of MUTYH, OGG1, and MTH1 were significantly decreased in both the WT (Figure 5(C,C1-C3), $p<0.01$ ) and APP/PS1 (Figure 5(D,D1-D3), $p<0.01$ ) mouse brains, suggesting that HDI may induce DNA damage, resulting in downstream events leading to neuron loss.

\subsection{Changes in Apoptosis and Autophagy-Related Proteins in the Brains of HDI-Treated Mice}

Iron overload and oxidative damage are known to drive neuronal cell death $[33,34]$. Therefore, we determined whether APP/PS1 mice developed the same rate of neuron loss as WT mice, with or without HDI. Apoptosis and autophagy are the main causes of neuron loss in AD-affected brains [35-38]. In HDI-treated WT mice, HDI significantly induced apoptosis through an increase in the expression of PARP1, cleaved-caspase 3 and AIF, but the Bcl-2/Bax ratio in the brain was not significantly different between HDI-treated and untreated WT mice (Figure 6(A,A1-A6), $p<0.05$ or $p<0.01$, respectively). Similar changes in apoptosis-associated proteins were seen in the brains of HDI-treated AD mice relative to their respective controls, although these changes were weaker (Figure 6(B,B1-B6), $p<0.05$ or $p<0.01$, respectively). 


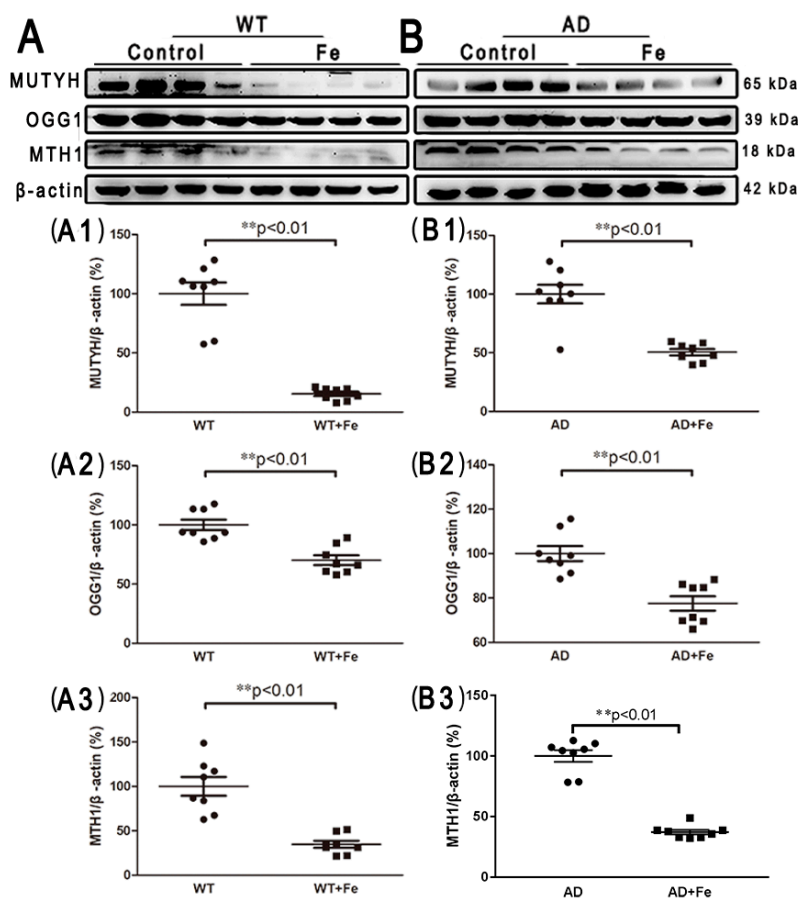

Figure 5. HDI-induced oxidative DNA damage in the mouse brain. (A, B) Western blot analysis of MutY homologous DNA glycosidase (MUTYH), 8-hydroxyguanine DNA glycosidase (OGG1), and 8-hydroxy guanine nucleotidase (MTH1). (A1-A3, B1-B3) Quantitative analyses of Western blot for MUTYH, OGG1, and MTH1. $\beta$-actin was used as an internal control. All results are presented as the mean $\pm \operatorname{SEM}(n=8) .{ }^{* *} p<0.01$.
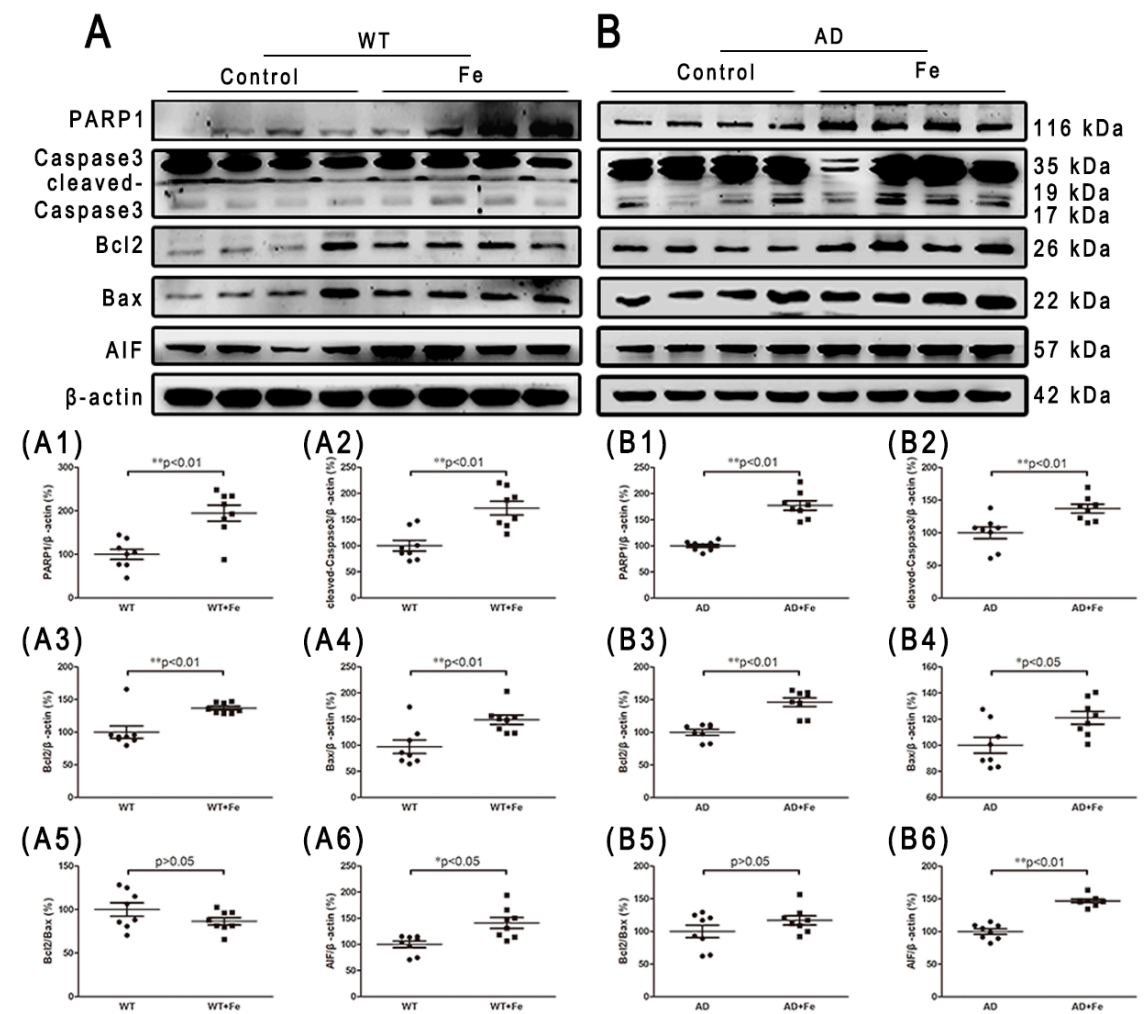

Figure 6. Changes in apoptosis-related proteins in the brains of HDI-treated mice. (A, B) Western blot analysis of PARP1, caspase 3, Bcl2, Bax, and AIF. (A1-A6, B1-B6) Quantitative analyses of Western blot for PARP1, caspase 3, Bcl2, Bax and AIF. $\beta$-actin was used as an internal control. All results are presented as the mean $\pm \operatorname{SEM}(n=8) .{ }^{*} p<0.05,{ }^{* *} p<0.01$. 
Given the prominent role of chronic iron exposure in $\mathrm{AD}$, and the increased autophagy latency in the development of severe neuron loss caused by iron accumulation, we then investigated the contribution of autophagy to brain damage. $\mathrm{m}$-TOR is an evolutionarily conserved PI3-kinase family member that plays a key role in integrating different biochemical and growth factor signals, and regulates the occurrence of autophagy [39]. We found that HDI treatment did not significantly affect $\mathrm{m}$-TOR expression in WT mice, but significantly increased its expression in AD model mice (Figure 7(A1,B1), $p<0.01$ ), whereas HDI treatment significantly decreased $p-m-T O R$ expression in both groups (Figure $7(\mathrm{~A} 2, \mathrm{~B} 2), p<0.01)$. Calpain, which is independent of $\mathrm{m}$-TOR, participates in intracellular autophagy and apoptosis by cleaving various protein substrates [40]. Here, calpain-1 protein expression was significantly higher in the brains of HDI-treated WT and APP/PS1 mice than in the brains of the respective controls (Figure 7(A3,B3), $p<0.01$ ). Next, the protein levels of Beclin-1, LC3A/B, and p62, which are reliable markers of autophagy [41], were probed. We found that the level of p62 was dramatically elevated by HDI treatment in the brains of APP/PS1 mice (Figure 7(B6), $p<0.01$ ), whereas the levels of Beclin-1 and LC3A/B were significantly increased in the brains of both WT and APP/PS1 mice after HDI treatment (Figure 7(A4,A5,B4,B5), $p<0.05$ or $p<0.01$, respectively).

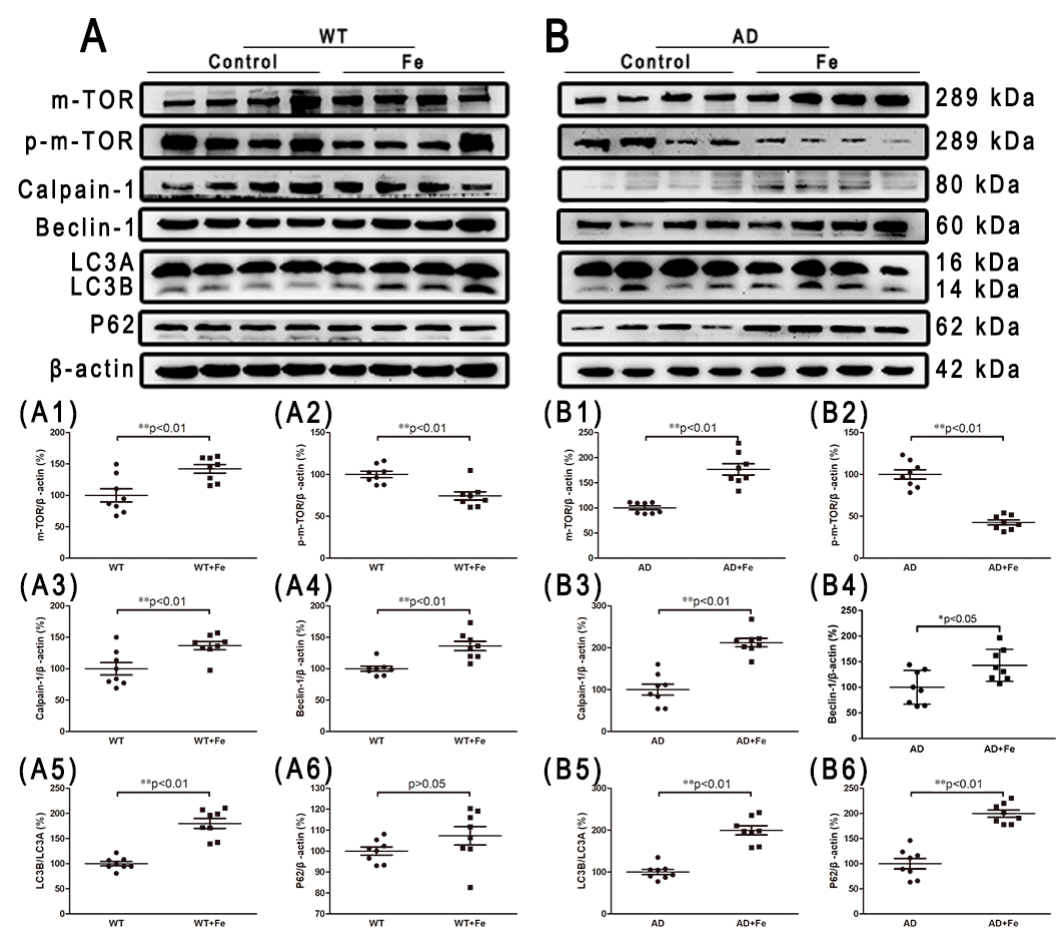

Figure 7. Changes in autophagy-related proteins in the brains of HDI-treated mice. (A, B) Western blot analysis of m-TOR, p-m-TOR, calpain 1, beclin 1, LC3 A/B, and P62. (A1-A6, B1-B6) Quantitative analyses of Western blot for m-TOR, p-m-TOR, calpain 1, beclin 1, LC3 A/B, and P62. $\beta$-actin was used as an internal control. All results are presented as the mean $\pm \operatorname{SEM}(n=8) .{ }^{*} p<0.05,{ }^{* *} p<0.01$.

Taken together, our results suggest that excessive iron exposure plays a critical role in regulating neuron loss.

\section{Discussion}

Despite the evidence regarding the pathological accumulation of iron in AD brains [42,43], only a few studies have demonstrated that iron exposure can result in iron entering the brain, leading to possible protein aggregation and neuron vulnerability. In the present study, we systematically showed that chronic exposure to iron for mice caused a disorder of membrane-transport protein function and intracellular iron homeostasis, and resulted in a significant increase in ROS and free radical MDA, ultimately leading to neuron and glial cell dysfunction and even neuron loss. 
Experimental iron overload using dietary supplementation with iron in the mouse is a well-established model [44,45]. Recent studies have found that the administration of a chronic lipophilic iron diet for 12 months significantly elevated brain iron and L-ferritin stores in C57BL6 mice and APP mice, respectively [46,47]. This present study investigated whether chronic administration of high concentrations of iron could alter brain iron levels, and then contribute to neuronal degeneration or the formation of $A \beta$ plaques in vivo. In contrast to the aforementioned studies, but in accordance with our previous study using APP/PS1 mice [48], exposure to chronic high iron in drinking water resulted in a nonsignificant elevation $(p>0.05)$ in brain iron levels in both WT and APP/PS1 mice; however, compared with the control mice, the HDI-treated mice showed upregulated expression of DMT1 and Fpn, and downregulated expression of TFR. Apparently, neurocytes can both inhibit ferric iron internalization into the cytosol via downregulating TFR, so that the internalized ferric iron is reduced to ferrous iron via upregulating DMT1, and encourage ferrous iron export by upregulating Fpn $[7,49]$. This suggests that neural cells may be protected by an increased rate of iron export under such conditions. In addition, Perl's staining analysis revealed no significant difference in iron-positive cells in the cortex and hippocampal regions between WT and APP/PS1 mice. A $\beta$ has been shown to bind ferrous ions [50], suggesting that accumulation of $A \beta$ might sequester iron and contribute to iron homeostasis in the brain of APP/PS1 mice. These results suggest that the brain has mechanisms to tightly control the level of iron entering the brain and neurocytes, but these mechanisms may become corrupt with age and/or chronic administration [51,52].

Our previous work revealed that chronic iron exposure increases $A \beta$ deposition, tau hyperphosphorylation, and synapse loss, leading to an exacerbation of cognitive dysfunction in 9-month-old APP/PS1 mice [48,53,54]. Although the dose of iron used in this experiment was much lower than that used in the previous work, our iron-loaded mouse models showed an apparent increase in $\mathrm{A} \beta$ plaque in 12-month-old APP/PS1 mice, and a possible decrease in NeuN expression in 12-month-old WT and APP/PS1 mice, when compared to the respective controls. Using Western blot, we confirmed that the expression level of NeuN protein was significantly decreased by HDI treatment. Meanwhile, Nissl body levels were also decreased by HDI treatment in both APP/PS1 mice and WT littermate controls, indicating that the lower level of NeuN expression could be attributable to iron-induced neuron loss. However, iron overload in our model also impacted the gliocyte population, as we observed a significant increase in GFAP-positive astrocytes and Iba1-positive microglia. Our data are consistent with reports that iron accumulation and overload are associated with an increase in number, and greater activation of, microglia and astrocytes in aged brains, as well as in brains from individuals who had AD [46,55-59]. Astrocytes are specialized for blockading and detoxifying nontransferrin-bound iron [60,61], and microglia show exponentially higher iron content than neurons or astrocytes [62]. Therefore, astrocytes and microglia may play a crucial role in maintaining neuronal function in the HDI-treated brain, through iron trafficking and storage [63].

Next, we aimed to understand the mechanisms underlying the increase in neuron loss observed in HDI-treated WT and APP/PS1 mouse brains. A variety of neurodegenerative diseases are associated with iron deposition and accompanied by brain tissue oxidative stress injury [64]. ROS levels reflect intracellular oxidative stress, and MDA content indirectly reflects the severity of the free radical attack on cells. As expected, the results showed that the levels of ROS and MDA were significantly increased after HDI treatment, suggesting that HDI induced and aggravated oxidative stress in both the WT and APP/PS1 mouse brains, especially in the former. Concurrently, a decrease in the expression of the antioxidant enzymes $\mathrm{XCT}, \mathrm{GPX} 4$, and SOD1 was associated with increased free radical generation in the APP/PS1 mouse brain after HDI treatment, whereas the expression levels of these antioxidants were significantly increased by HDI treatment in the WT mouse brain. These observations indicate that the iron alterations not only induce oxidative damage, but also trigger sufficient cellular compensation under normal physiological conditions [65], while the compensatory response to iron-induced oxidative damage may be restricted under conditions of $A \beta$ accumulation. Although the specific molecular targets by which iron induces oxidative stress are not known, iron is known to 
be involved in brain oxidative mitochondria dysfunction and DNA damage $[65,66]$. Here, our results showed that high-iron treatment significantly reduced the expression of three DNA repair proteins (MUTYH, OGG1 and MTH1) in the brain, suggesting that high-iron treatment decreased the rate of DNA repair and increased DNA oxidation and damage, finally causing the downstream events leading to cell death $[67,68]$.

In fact, iron and ROS have been accepted as important mediators of cell death in many pathological processes that involve altered iron homeostasis. Studies have shown that iron overload in the AD brain can induce oxidative stress, leading to protein aggregation and neuron vulnerability [69,70]. Thus, we further determined which phenotype of neuron death is induced by long-term iron exposure in our system. Caspase is a major participant in AD-related apoptotic cascades, and AIF-induced cell death may also contribute to the neuron death observed in chronic neurodegenerative diseases [71]. As expected, our results showed that the expression of the apoptosis-promoting proteins Bax, PARP1, and AIF was increased after caspase 3 was cleaved in the brain of HDI-treated WT and APP/PS1 mice. Although the ratio of Bcl-2/Bax was not significantly reduced by HDI treatment, we can still speculate that caspase-dependent apoptosis took place in our system. We then examined levels of autophagy markers (m-TOR, calpain-1, Beclin-1, LC3A/B, and p62) in 12-month-old WT and APP/PS1 mice with or without chronic iron exposure. We found that levels of $\mathrm{p}-\mathrm{m}-\mathrm{TOR}$ were dramatically decreased by HDI treatment, whereas the levels of calpain-1, Beclin-1, LC3A/B, and p62 were elevated. $\mathrm{m}$-TOR is a variety of intracellular protein receptor that regulates the occurrence of autophagy [39]. The observed suppressed phosphorylation of m-TOR indicated that autophagy is induced by HDI treatment in the brain of both WT and APP/PS1 mice [72]. Calpain, which acts independently of m-TOR [40], can participate in intracellular autophagy and apoptosis by cleaving various protein substrates, which is a pathway that is known to be negatively regulated by $\mathrm{m}$-TOR [73]. Interestingly, our previous data provided a possible link between LA and the decreased calcium content of brain tissue in LA-treated P301S Tau transgenic mice [19]. Combined with our current data, these observations suggest that HDI treatment leads to calcium-dependent calpain 1 activation, a decrease in the number of mitochondria, and subsequent activation of autophagy and apoptosis [73,74]. Furthermore, the protein expression levels of Beclin-1, LC3A/B, and p62, several reliable markers of autophagy [41], were significantly higher in HDI-treated mice than those in the respective controls. Despite conflicting knowledge about the role of autophagy in AD [75], these results indicate that autophagy was induced or elevated by HDI treatment, and may augment the neuronal loss triggered by chronic iron exposure. In addition to the aforementioned "classic" mechanisms of neuron loss, an iron- and lipid-peroxidation-dependent pathway of cell death, called ferroptosis, is currently being investigated as a possible pathomechanism in AD [24,76,77]. Here, we found that under normal physiological conditions, chronic iron exposure can not only increase the production of ROS, but also activate the antioxidant enzymes xCT and GPX4, which inhibit the occurrence of ferroptosis [78]. However, long-term high-iron treatment may increase ROS but decrease the levels of XCT and GPX4, suggesting that ferroptosis is induced or increased in the brain tissues of iron-treated APP/PS1 mice. Collectively, these in vivo studies clearly indicate that chronic iron exposure results in neuronal loss due to apoptosis, autophagy, and ferroptosis, hence increasing the risk for the development of AD. Further studies are required to clarify whether ferroptosis is responsible for the iron-mediated cell death observed in the brains of WT mice.

In summary, we demonstrated that chronic high-dose iron exposure interferes with iron homeostasis and distribution, increases oxidative stress, exacerbates mitochondria dysfunction and DNA oxidative damage, and induces neuronal loss (apoptosis, autophagy, and ferroptosis); however, long-term high-dose iron administration following iron overload might trigger protective antioxidant, anti-apoptosis, and autophagy signaling. The present data, together with previous reports $[19,48,53,54]$, suggest that environmental exposure to iron in drinking water or food might contribute to the evolution and progression of AD. Of course, many of our findings are limited to qualitative histological analyses 
and protein analyses, and the identification of the precise molecular pathways of iron-dependent neuronal loss is required to support our findings.

Author Contributions: L.-B.L., performed most of the experiments and analyzed the data; R.C., S.Z., and S.-F.X., generated and validated the mouse model; Y.-H.Z., and Y.-G.F., contributed to discussion; H.-L.L., contributed to AAS detection; C.G., designed and wrote manuscript. All authors have read and approved the final manuscript.

Funding: This study was financially supported by the Natural Science Foundation of China (U1608282).

Conflicts of Interest: The authors declare that no conflict of interests.

\section{References}

1. Ridler, C. Alzheimer disease: BACE1 inhibitors block new Abeta plaque formation. Nat. Rev. Neurol. 2018. [CrossRef] [PubMed]

2. Di Domenico, F.; Tramutola, A.; Foppoli, C.; Head, E.; Perluigi, M.; Butterfield, D.A. mTOR in Down syndrome: Role in Ass and tau neuropathology and transition to Alzheimer disease-like dementia. Free Radic. Biol. Med. 2018, 114, 94-101. [CrossRef] [PubMed]

3. Vargas, L.M.; Cerpa, W.; Munoz, F.J.; Zanlungo, S.; Alvarez, A.R. Amyloid-beta oligomers synaptotoxicity: The emerging role of EphA4/c-Abl signaling in Alzheimer's disease. BBA 2018, 1864, 1148-1159.

4. Tao, L.X.; Huang, X.T.; Chen, Y.T.; Tang, X.C.; Zhang, H.Y. Acetylcholinesterase-independent protective effects of huperzine A against iron overload-induced oxidative damage and aberrant iron metabolism signaling in rat cortical neurons. Acta Pharmacol. Sin. 2016, 37, 1391-1400. [CrossRef] [PubMed]

5. Gong, J.; Du, F.; Qian, Z.M.; Luo, Q.Q.; Sheng, Y.; Yung, W.H.; Xu, Y.X.; Ke, Y. Pre-treatment of rats with ad-hepcidin prevents iron-induced oxidative stress in the brain. Free Radic. Biol. Med. 2016, 90, 126-132. [CrossRef] [PubMed]

6. Du, F.; Qian, Z.M.; Luo, Q.; Yung, W.H.; Ke, Y. Hepcidin Suppresses Brain Iron Accumulation by Downregulating Iron Transport Proteins in Iron-Overloaded Rats. Mol. Neurobiol. 2015, 52, 101-114. [CrossRef] [PubMed]

7. Zhou, Z.D.; Tan, E.K. Iron regulatory protein (IRP)-iron responsive element (IRE) signaling pathway in human neurodegenerative diseases. Mol. Neurodegener. 2017, 12, 75. [CrossRef] [PubMed]

8. Squitti, R. Metals in Alzheimer's disease: A systemic perspective. Front Biosci. (Landmark Ed.) 2012, 17, 451-472. [CrossRef] [PubMed]

9. Duce, J.A.; Tsatsanis, A.; Cater, M.A.; James, S.A.; Robb, E.; Wikhe, K.; Leong, S.L.; Perez, K.; Johanssen, T.; Greenough, M.A.; et al. Iron-export ferroxidase activity of beta-amyloid precursor protein is inhibited by zinc in Alzheimer's disease. Cell 2010, 142, 857-867. [CrossRef] [PubMed]

10. McCarthy, R.C.; Park, Y.H.; Kosman, D.J. sAPP modulates iron efflux from brain microvascular endothelial cells by stabilizing the ferrous iron exporter ferroportin. EMBO Rep. 2014, 15, 809-815. [CrossRef] [PubMed]

11. Good, P.F.; Perl, D.P.; Bierer, L.M.; Schmeidler, J. Selective accumulation of aluminum and iron in the neurofibrillary tangles of Alzheimer's disease: A laser microprobe (LAMMA) study. Ann. Neurol. 1992, 31, 286-292. [CrossRef] [PubMed]

12. Hare, D.; Ayton, S.; Bush, A.; Lei, P. A delicate balance: Iron metabolism and diseases of the brain. Front. Aging Neurosci. 2013, 5, 34. [CrossRef] [PubMed]

13. Sayre, L.M.; Perry, G.; Harris, P.L.; Liu, Y.; Schubert, K.A.; Smith, M.A. In situ oxidative catalysis by neurofibrillary tangles and senile plaques in Alzheimer's disease: A central role for bound transition metals. J. Neurochem. 2000, 74, 270-279. [CrossRef] [PubMed]

14. Sripetchwandee, J.; Wongjaikam, S.; Krintratun, W.; Chattipakorn, N.; Chattipakorn, S.C. A combination of an iron chelator with an antioxidant effectively diminishes the dendritic loss, tau-hyperphosphorylation, amyloids-beta accumulation and brain mitochondrial dynamic disruption in rats with chronic iron-overload. Neuroscience 2016, 332, 191-202. [CrossRef] [PubMed]

15. Kondziella, D.; Zetterberg, H. Hyperphosphorylation of tau protein in superficial CNS siderosis. J. Neurol. Sci. 2008, 273, 130-132. [CrossRef] [PubMed]

16. Lovell, M.A.; Xiong, S.; Xie, C.; Davies, P.; Markesbery, W.R. Induction of hyperphosphorylated tau in primary rat cortical neuron cultures mediated by oxidative stress and glycogen synthase kinase-3. JAD 2004, 6, 659-671. [CrossRef] [PubMed] 
17. Gamblin, T.C.; King, M.E.; Kuret, J.; Berry, R.W.; Binder, L.I. Oxidative regulation of fatty acid-induced tau polymerization. Biochemistry 2000, 39, 14203-14210. [CrossRef] [PubMed]

18. Lei, P.; Ayton, S.; Finkelstein, D.I.; Spoerri, L.; Ciccotosto, G.D.; Wright, D.K.; Wong, B.X.; Adlard, P.A.; Cherny, R.A.; Lam, L.Q.; et al. Tau deficiency induces parkinsonism with dementia by impairing APP-mediated iron export. Nat. Med. 2012, 18, 291-295. [CrossRef] [PubMed]

19. Zhang, Y.H.; Wang, D.W.; Xu, S.F.; Zhang, S.; Fan, Y.G.; Yang, Y.Y.; Guo, S.Q.; Wang, S.; Guo, T.; Wang, Z.Y; et al. Alpha-Lipoic acid improves abnormal behavior by mitigation of oxidative stress, inflammation, ferroptosis, and tauopathy in P301S Tau transgenic mice. Redox Biol. 2018, 14, 535-548. [CrossRef] [PubMed]

20. Smith, M.A.; Harris, P.L.; Sayre, L.M.; Perry, G. Iron accumulation in Alzheimer disease is a source of redox-generated free radicals. Proc. Natl. Acad. Sci. USA 1997, 94, 9866-9868. [CrossRef]

21. Zhang, B.; Carroll, J.; Trojanowski, J.Q.; Yao, Y.; Iba, M.; Potuzak, J.S.; Hogan, A.M.; Xie, S.X.; Ballatore, C.; Smith, A.B.; et al. The microtubule-stabilizing agent, epothilone D, reduces axonal dysfunction, neurotoxicity, cognitive deficits, and Alzheimer-like pathology in an interventional study with aged tau transgenic mice. J. Neurosci. 2012, 32, 3601-3611. [CrossRef] [PubMed]

22. Baek, S.S.; Kim, S.H. Treadmill exercise ameliorates symptoms of Alzheimer disease through suppressing microglial activation-induced apoptosis in rats. J. Exerc. Rehabil. 2016, 12, 526-534. [CrossRef] [PubMed]

23. Zhang, L.; Wang, L.; Wang, R.; Gao, Y.; Che, H.; Pan, Y.; Fu, P. Evaluating the Effectiveness of GTM-1, Rapamycin, and Carbamazepine on Autophagy and Alzheimer Disease. Med. Sci. Monit. 2017, 23, 801-808. [CrossRef] [PubMed]

24. Hambright, W.S.; Fonseca, R.S.; Chen, L.; Na, R.; Ran, Q. Ablation of ferroptosis regulator glutathione peroxidase 4 in forebrain neurons promotes cognitive impairment and neurodegeneration. Redox Biol. 2017, 12, 8-17. [CrossRef] [PubMed]

25. Matsumura, A.; Emoto, M.C.; Suzuki, S.; Iwahara, N.; Hisahara, S.; Kawamata, J.; Suzuki, H.; Yamauchi, A.; Sato-Akaba, H.; Fujii, H.G.; et al. Evaluation of oxidative stress in the brain of a transgenic mouse model of Alzheimer disease by in vivo electron paramagnetic resonance imaging. Free Radic. Biol. Med. 2015, 85, 165-173. [CrossRef] [PubMed]

26. Anderson, A.J.; Stoltzner, S.; Lai, F.; Su, J.; Nixon, R.A. Morphological and biochemical assessment of DNA damage and apoptosis in Down syndrome and Alzheimer disease, and effect of postmortem tissue archival on TUNEL. Neurobiol. Aging 2000, 21, 511-524. [CrossRef]

27. Maccecchini, M.L.; Chang, M.Y.; Pan, C.; John, V.; Zetterberg, H.; Greig, N.H. Posiphen as a candidate drug to lower CSF amyloid precursor protein, amyloid-beta peptide and tau levels: Target engagement, tolerability and pharmacokinetics in humans. J. Neurol Neurosurg. Psychiatry 2012, 83, 894-902. [CrossRef] [PubMed]

28. Pelizzoni, I.; Zacchetti, D.; Campanella, A.; Grohovaz, F.; Codazzi, F. Iron uptake in quiescent and inflammation-activated astrocytes: A potentially neuroprotective control of iron burden. BBA 2013, 1832, 1326-1333. [CrossRef] [PubMed]

29. Lechowski, L.; Dieudonne, B.; Tortrat, D.; Teillet, L.; Robert, P.H.; Benoit, M.; Forette, B.; Vellas, B.; Phrc, R.F. Role of behavioural disturbance in the loss of autonomy for activities of daily living in Alzheimer patients. Int. J. Geriatr. Psychiatry 2003, 18, 977-982. [CrossRef] [PubMed]

30. Kumar, S.; Zomorrodi, R.; Ghazala, Z.; Goodman, M.S.; Blumberger, D.M.; Cheam, A.; Fischer, C.; Daskalakis, Z.J.; Mulsant, B.H.; Pollock, B.G.; et al. Extent of Dorsolateral Prefrontal Cortex Plasticity and Its Association With Working Memory in Patients With Alzheimer Disease. JAMA Psychiatry 2017, 74, 1266-1274. [CrossRef] [PubMed]

31. Valko, M.; Leibfritz, D.; Moncol, J.; Cronin, M.T.; Mazur, M.; Telser, J. Free radicals and antioxidants in normal physiological functions and human disease. Int. J. Biochem. Cell Biol. 2007, 39, 44-84. [CrossRef] [PubMed]

32. Imai, H.; Matsuoka, M.; Kumagai, T.; Sakamoto, T.; Koumura, T. Lipid Peroxidation-Dependent Cell Death Regulated by GPx4 and Ferroptosis. Curr. Top. Microbiol. Immunol. 2017, 403, 143-170. [PubMed]

33. Salkovic-Petrisic, M.; Knezovic, A.; Osmanovic-Barilar, J.; Smailovic, U.; Trkulja, V.; Riederer, P.; Amit, T.; Mandel, S.; Youdim, M.B. Multi-target iron-chelators improve memory loss in a rat model of sporadic Alzheimer's disease. Life Sci. 2015, 136, 108-119. [CrossRef] [PubMed] 
34. Sofic, E.; Salkovic-Petrisic, M.; Tahirovic, I.; Sapcanin, A.; Mandel, S.; Youdim, M.; Riederer, P. Brain catalase in the streptozotocin-rat model of sporadic Alzheimer's disease treated with the iron chelator-monoamine oxidase inhibitor, M30. J. Neural Transm. 2015, 122, 559-564. [CrossRef] [PubMed]

35. Ghasemi, M.; Mayasi, Y.; Hannoun, A.; Eslami, S.M.; Carandang, R. Nitric Oxide and Mitochondrial Function in Neurological Diseases. Neuroscience 2018, 376, 48-71. [CrossRef] [PubMed]

36. Gao, Z.; Shan, J.; Wang, B.; Qiao, L.; Chen, D.; Zhang, Y. DRAM Is Involved in Regulating Nucleoside Analog-Induced Neuronal Autophagy in a p53-Independent Manner. Mol. Neurobiol. 2018, 55, 1988-1997. [CrossRef] [PubMed]

37. Jaroonwitchawan, T.; Chaicharoenaudomrung, N.; Namkaew, J.; Noisa, P. Curcumin attenuates paraquat-induced cell death in human neuroblastoma cells through modulating oxidative stress and autophagy. Neurosci. Lett. 2017, 636, 40-47. [CrossRef] [PubMed]

38. Debye, B.; Schmulling, L.; Zhou, L.; Rune, G.; Beyer, C.; Johann, S. Neurodegeneration and NLRP3 inflammasome expression in the anterior thalamus of SOD1(G93A) ALS mice. Brain Pathol. 2018, 28, 14-27. [CrossRef] [PubMed]

39. Drapalo, K.; Jozwiak, J. Parkin, PINK1 and DJ1 as possible modulators of mTOR pathway in ganglioglioma. Int. J. Neurosci. 2018, 128, 167-174. [CrossRef] [PubMed]

40. Cho, H.I.; Kim, S.J.; Choi, J.W.; Lee, S.M. Genipin alleviates sepsis-induced liver injury by restoring autophagy. Br. J. Pharmacol. 2016, 173, 980-991. [CrossRef] [PubMed]

41. Zhao, H.; Yang, M.; Zhao, B. Beclin 1 and LC3 as predictive biomarkers for metastatic colorectal carcinoma. Oncotarget 2017, 8, 59058-59067. [CrossRef] [PubMed]

42. Zecca, L.; Youdim, M.B.; Riederer, P.; Connor, J.R.; Crichton, R.R. Iron, brain ageing and neurodegenerative disorders. Nat. Rev. Neurosci. 2004, 5, 863-873. [CrossRef] [PubMed]

43. Ward, R.J.; Zucca, F.A.; Duyn, J.H.; Crichton, R.R.; Zecca, L. The role of iron in brain ageing and neurodegenerative disorders. Lancet Neurol. 2014, 13, 1045-1060. [CrossRef]

44. Unger, E.L.; Beard, J.L.; Jones, B.C. Iron regulation in C57BLI6 and DBA/2 mice subjected to iron overload. Nutr. Neurosci. 2007, 10, 89-95. [CrossRef] [PubMed]

45. Garcia-Yebenes, I.; Sobrado, M.; Moraga, A.; Zarruk, J.G.; Romera, V.G.; Pradillo, J.M.; Perez de la Ossa, N.; Moro, M.A.; Davalos, A.; Lizasoain, I. Iron overload, measured as serum ferritin, increases brain damage induced by focal ischemia and early reperfusion. Neurochem. Int. 2012, 61, 1364-1369. [CrossRef] [PubMed]

46. Peters, D.G.; Pollack, A.N.; Cheng, K.C.; Sun, D.; Saido, T.; Haaf, M.P.; Yang, Q.X.; Connor, J.R.; Meadowcroft, M.D. Dietary lipophilic iron alters amyloidogenesis and microglial morphology in Alzheimer's disease knock-in APP mice. Metallomics 2018, 10, 426-443. [CrossRef] [PubMed]

47. Peters, D.G.; Purnell, C.J.; Haaf, M.P.; Yang, Q.X.; Connor, J.R.; Meadowcroft, M.D. Dietary lipophilic iron accelerates regional brain iron-load in C57BL6 mice. Brain Struct. Funct. 2018, 223, 1519-1536. [CrossRef] [PubMed]

48. Guo, C.; Wang, T.; Zheng, W.; Shan, Z.Y.; Teng, W.P.; Wang, Z.Y. Intranasal deferoxamine reverses iron-induced memory deficits and inhibits amyloidogenic APP processing in a transgenic mouse model of Alzheimer's disease. Neurobiol. Aging 2013, 34, 562-575. [CrossRef] [PubMed]

49. Mills, E.; Dong, X.P.; Wang, F.; Xu, H. Mechanisms of brain iron transport: Insight into neurodegeneration and CNS disorders. Future Med. Chem. 2010, 2, 51-64. [CrossRef] [PubMed]

50. Boopathi, S.; Kolandaivel, P. Fe(2+) binding on amyloid beta-peptide promotes aggregation. Proteins 2016, 84, 1257-1274. [CrossRef] [PubMed]

51. Fredriksson, A.; Schroder, N.; Eriksson, P.; Izquierdo, I.; Archer, T. Neonatal iron exposure induces neurobehavioural dysfunctions in adult mice. Toxicol. Appl. Pharmacol. 1999, 159, 25-30. [CrossRef] [PubMed]

52. Caldwell, M.A.; He, X.; Wilkie, N.; Pollack, S.; Marshall, G.; Wafford, K.A.; Svendsen, C.N. Growth factors regulate the survival and fate of cells derived from human neurospheres. Nat. Biotechnol. 2001, 19, 475-479. [CrossRef] [PubMed]

53. Guo, C.; Wang, P.; Zhong, M.L.; Wang, T.; Huang, X.S.; Li, J.Y.; Wang, Z.Y. Deferoxamine inhibits iron induced hippocampal tau phosphorylation in the Alzheimer transgenic mouse brain. Neurochem. Int. 2013, 62, 165-172. [CrossRef] [PubMed]

54. Guo, C.; Zhang, Y.X.; Wang, T.; Zhong, M.L.; Yang, Z.H.; Hao, L.J.; Chai, R.; Zhang, S. Intranasal deferoxamine attenuates synapse loss via up-regulating the P38/HIF-1alpha pathway on the brain of APP/PS1 transgenic mice. Front. Aging Neurosci. 2015, 7, 104. [CrossRef] [PubMed] 
55. Healy, S.; McMahon, J.; Owens, P.; FitzGerald, U. Significant glial alterations in response to iron loading in a novel organotypic hippocampal slice culture model. Sci. Rep. 2016, 6, 36410. [CrossRef] [PubMed]

56. Lopes, K.O.; Sparks, D.L.; Streit, W.J. Microglial dystrophy in the aged and Alzheimer's disease brain is associated with ferritin immunoreactivity. Glia 2008, 56, 1048-1060. [CrossRef] [PubMed]

57. Rathore, K.I.; Redensek, A.; David, S. Iron homeostasis in astrocytes and microglia is differentially regulated by TNF-alpha and TGF-beta1. Glia 2012, 60, 738-750. [CrossRef] [PubMed]

58. Bishop, G.M.; Dang, T.N.; Dringen, R.; Robinson, S.R. Accumulation of non-transferrin-bound iron by neurons, astrocytes, and microglia. Neurotox. Res. 2011, 19, 443-451. [CrossRef] [PubMed]

59. Keenan, B.M.; Robinson, S.R.; Bishop, G.M. Effects of carboxylic acids on the uptake of non-transferrin-bound iron by astrocytes. Neurochem. Int. 2010, 56, 843-849. [CrossRef] [PubMed]

60. Dringen, R.; Bishop, G.M.; Koeppe, M.; Dang, T.N.; Robinson, S.R. The pivotal role of astrocytes in the metabolism of iron in the brain. Neurochem. Res. 2007, 32, 1884-1890. [CrossRef] [PubMed]

61. Hoepken, H.H.; Korten, T.; Robinson, S.R.; Dringen, R. Iron accumulation, iron-mediated toxicity and altered levels of ferritin and transferrin receptor in cultured astrocytes during incubation with ferric ammonium citrate. J. Neurochem. 2004, 88, 1194-1202. [CrossRef] [PubMed]

62. Urrutia, P.; Aguirre, P.; Esparza, A.; Tapia, V.; Mena, N.P.; Arredondo, M.; Gonzalez-Billault, C.; Nunez, M.T. Inflammation alters the expression of DMT1, FPN1 and hepcidin, and it causes iron accumulation in central nervous system cells. J. Neurochem. 2013, 126, 541-549. [CrossRef] [PubMed]

63. Belaidi, A.A.; Bush, A.I. Iron neurochemistry in Alzheimer's disease and Parkinson's disease: Targets for therapeutics. J. Neurochem. 2016, 139 (Suppl. 1), 179-197. [CrossRef] [PubMed]

64. Schipper, H.M. Glial HO-1 expression, iron deposition and oxidative stress in neurodegenerative diseases. Neurotox. Res. 1999, 1, 57-70. [CrossRef] [PubMed]

65. Piloni, N.E.; Caro, A.A.; Puntarulo, S. Iron overload prevents oxidative damage to rat brain after chlorpromazine administration. Biometals 2018, 31, 567-570. [CrossRef] [PubMed]

66. Carocci, A.; Catalano, A.; Sinicropi, M.S.; Genchi, G. Oxidative stress and neurodegeneration: The involvement of iron. Biometals 2018, 31, 715-735. [CrossRef] [PubMed]

67. Abolhassani, N.; Leon, J.; Sheng, Z.; Oka, S.; Hamasaki, H.; Iwaki, T.; Nakabeppu, Y. Molecular pathophysiology of impaired glucose metabolism, mitochondrial dysfunction, and oxidative DNA damage in Alzheimer's disease brain. Mech. Ageing Dev. 2017, 161, 95-104. [CrossRef] [PubMed]

68. Mitra, J.; Guerrero, E.N.; Hegde, P.M.; Wang, H.; Boldogh, I.; Rao, K.S.; Mitra, S.; Hegde, M.L. New perspectives on oxidized genome damage and repair inhibition by pro-oxidant metals in neurological diseases. Biomolecules 2014, 4, 678-703. [CrossRef] [PubMed]

69. Smith, C.D.; Carney, J.M.; Starke-Reed, P.E.; Oliver, C.N.; Stadtman, E.R.; Floyd, R.A.; Markesbery, W.R. Excess brain protein oxidation and enzyme dysfunction in normal aging and in Alzheimer disease. Proc. Natl. Acad. Sci. USA 1991, 88, 10540-10543. [CrossRef]

70. Rogers, J.T.; Lahiri, D.K. Metal and inflammatory targets for Alzheimer's disease. Curr. Drug Targ. 2004, 5, 535-551. [CrossRef]

71. Lee, J.H.; Cheon, Y.H.; Woo, R.S.; Song, D.Y.; Moon, C.; Baik, T.K. Evidence of early involvement of apoptosis inducing factor-induced neuronal death in Alzheimer brain. Anat. Cell Biol. 2012, 45, 26-37. [CrossRef] [PubMed]

72. Duarte-Silva, S.; Silva-Fernandes, A.; Neves-Carvalho, A.; Soares-Cunha, C.; Teixeira-Castro, A.; Maciel, P. Combined therapy with $\mathrm{m}$-TOR-dependent and -independent autophagy inducers causes neurotoxicity in a mouse model of Machado-Joseph disease. Neuroscience 2016, 313, 162-173. [CrossRef] [PubMed]

73. Williams, A.; Sarkar, S.; Cuddon, P.; Ttofi, E.K.; Saiki, S.; Siddiqi, F.H.; Jahreiss, L.; Fleming, A.; Pask, D.; Goldsmith, P.; et al. Novel targets for Huntington's disease in an mTOR-independent autophagy pathway. Nat. Chem. Biol. 2008, 4, 295-305. [CrossRef] [PubMed]

74. So, K.Y.; Lee, B.H.; Oh, S.H. The critical role of autophagy in cadmium-induced immunosuppression regulated by endoplasmic reticulum stress-mediated calpain activation in RAW264.7 mouse monocytes. Toxicology 2018, 393, 15-25. [CrossRef] [PubMed]

75. Bove, J.; Martinez-Vicente, M.; Vila, M. Fighting neurodegeneration with rapamycin: Mechanistic insights. Nat. Rev. Neurosci. 2011, 12, 437-452. [CrossRef] [PubMed] 
76. Dixon, S.J.; Lemberg, K.M.; Lamprecht, M.R.; Skouta, R.; Zaitsev, E.M.; Gleason, C.E.; Patel, D.N.; Bauer, A.J.; Cantley, A.M.; Yang, W.S.; et al. Ferroptosis: An iron-dependent form of nonapoptotic cell death. Cell 2012, 149, 1060-1072. [CrossRef] [PubMed]

77. Lane, D.J.R.; Ayton, S.; Bush, A.I. Iron and Alzheimer's Disease: An Update on Emerging Mechanisms. JAD 2018, 64, S379-S395. [CrossRef] [PubMed]

78. Maiorino, M.; Conrad, M.; Ursini, F. GPx4, Lipid Peroxidation, and Cell Death: Discoveries, Rediscoveries, and Open Issues. Antioxid. Redox Sign. 2017, 29, 61-74. [CrossRef] [PubMed]

(C) 2019 by the authors. Licensee MDPI, Basel, Switzerland. This article is an open access article distributed under the terms and conditions of the Creative Commons Attribution (CC BY) license (http:/ / creativecommons.org/licenses/by/4.0/). 